\title{
Filosofía intercultural: una propuesta para nuestro tiempo
}

RESUMEN: Es necesario orientar nuestro pensar y nuestra acción por medio del diálogo, acción oriunda de las diferencias, única actitud capaz de propiciar la confrontación entre los diversos discursos y argumentos por medio de los cuales se ampliarán las posibilidades enriquecedoras en una realidad marcada por las diferencias. Por lo tanto, la propuesta de una nueva filosofía que oriente el proceso educacional brasileño, lugar de mundos de vida y de pensamientos plurales, se hace necesaria.

ABSTRACT: It is necessary to focus our thought and action through the dialogue, an action born from differences and the only attitude that may propitiate a confrontation bet-

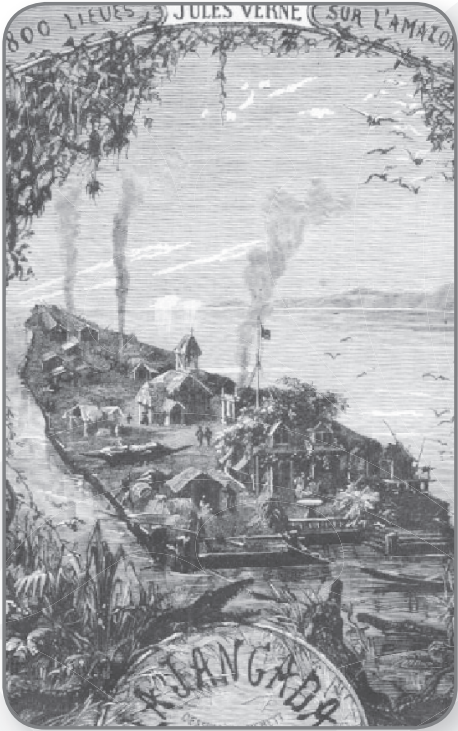

ween the discourses and arguments, which may widen the possibilities in a reality marked by differences. Thus, the proposal of a new philosophy in order to guide the Brazilian educational process - a place of plural lifeworlds and thought is necessary. 


\section{Consideraciones iniciales}

os tiempos actuales, marcados por la diversidad, nos muestran que vivimos en un contexto donde las razones absolutas no ofrecen más condiciones para iluminar un mundo constituido por culturas heterogéneas. Lo cotidiano de la vida académica nos da la oportunidad de contacto con personas pertenecientes a diferentes culturas, que se orientan por valores espirituales distintos. Siendo así, se hace necesario guiar nuestra acción, que anhela ser educativa, por caminos no pautados por la seguridad de una tradición heredada, cristalizada. Se constata que, en nuestra educación formal, domina un descrédito al saber contextual, cuando se sabe que solamente la experiencia contextualizada nos va a decir lo que realmente es significativo para ser retomado, revalorizado en el sentido de venir a colaborar en la realización de lo humano, apuntando a lo que debe ser mantenido, recuperado por ser lo esencial, porque propio.
No raramente, las instituciones se orientan por conceptos considerados como ideales e irreductibles, como si el mundo humano existencial no fuese dinámico generado por el conocimiento advenido de las necesidades surgidas en el proceso de la existencia.

La autocrítica permanente acerca del comportamiento cultural nos lleva a la convicción de que el trabajo pedagógico, en los moldes tradicionales, es infecundo para la mediación como vía para una comunidad más justa. Las relaciones pedagógicas no pueden reducirse al mero intercambio de ideas abstractas, sino que deben versar sobre y entre las situaciones de lo humano. Debemos tener en mente que el acto pedagógico interfiere en seres humanos concretos, que están viviendo en este momento $y$, para tal menester, actúan en y dentro de contextos situados. Todo texto presupone un contexto en el cual es gestado y producido.

\section{Una nueva propuesta filosófica}

Necesitamos orientar nuestro pensar y nuestra acción por medio del diálogo, acción oriunda de las diferencias, única actitud capaz de propiciar la confrontación entre los diversos discursos y argumentos por medio de los cuales se ampliarán las posibilidades enriquecedoras en una realidad marcada por las dife- rencias. Por lo tanto, la propuesta de una nueva filosofía que oriente el proceso educacional brasilero, lugar de mundos de vida y de pensamientos plurales, se hace necesaria.

Tenemos la segura convicción de la necesidad de transformar, interculturalmente, la filosofía bra- 
silera, frente a la heterogeneidad cultural de sus pueblos. Partimos del presupuesto de que el estudio y la enseñanza de la filosofía tiene como objetivo colaborar para que el ser humano amplíe el conocimiento de si mismo, en la convivencia con el otro, mediante la confrontación práctico-reflexiva con los contextos de la vida y en interacción con el ambiente natural que lo acoge.

Brasil es un país con una población aproximada de 185 millones de habitantes que presentan las más diversas características culturales. Se habla un promedio de 300 lenguas entre indígenas, afro-brasileras y de pueblos inmigrantes, entre las variantes portuguesas.

Poblaciones que habitan diferentes áreas geográficas que van del bosque tropical a la región semiárida; de regiones montañosas hasta las vastas pampas del hemisferio sur, con la más variada topografía, vegetación, tipos de suelos y climas.
Todo eso hace con que los hábitos, la indumentaria, la alimentación y, consecuentemente, las tradiciones culturales que iluminan los espíritus de su pueblo, presenten una heterogeneidad admirable. Razones que justifican la necesidad de reorientar el proceso educacional, basado en una filosofía que acentúe, en su reflexión, la relación entre las culturas históricas, las culturas originarias y comunicables entre sí, y la realidad ahora vivenciada en el panorama del mundo contemporáneo.

Es necesario transformar, interculturalmente, los cursos de filosofía, basados en una antropología que repiense la constitución de los pueblos del Brasil, pautados por la búsqueda del reconocimiento de la identidad $y$, consecuentemente, de la valorización del Otro, que dé la oportunidad de romper con los mecanismos del silencio, haciéndose oír el eco de todas las voces, inclusive trayendo a la superficie las voces de las víctimas de la historia brasilera.

\section{Fundamentos para la nueva propuesta}

Dentro del panorama intelectual brasilero una de las orientaciones que nos ayudan al cuestionamiento y la comprensión de la formación y del sentido de las identidades culturales de nuestro país es la del antropólogo Darcy Ribeiro, en las cuales se identifican incidencias de interculturalidad dentro de su concepción de proce- so civilizador. ${ }^{2}$ Conocer su obra es un paso importante para poner los cimientos en la búsqueda de una propuesta filosófica que permita una aproximación a un pensamiento que atienda las reclamaciones del tiempo en que estamos viviendo.

Darcy Ribeiro une, en su trabajo, la especulación científica a la 
preocupación con lo social. Autor, que mismo guiado por el rigor científico, investiga no exclusivamente para alcanzar ese saber, sino movido mucho más por la responsabilidad que creía que debía tener todo intelectual con el contexto en el cual vive. Su perspectiva antropológica es comprometida con lo humano y colocada al servicio de los pueblos que investiga. Postura que nos ayuda a encontrar, a partir de su pensamiento, elementos que van a identificar $y$ singularizar a los diferentes grupos humanos brasileros, ofreciendo elementos para una hermenéutica de la constitución de la población que vive en el territorio brasilero.

A lo largo de su obra, va tejiendo la formación del pueblo brasilero a partir de su identidad no apenas étnica sino, y fundamentalmente cultural, proceso resultante, según él, de la evolución sociocultural dada en el intercambio con el ambiente natural. Propone una revisión crítica de la teoría evolucionista $^{3}$ una vez que, en su comprensión, el proceso de formación étnica en América Latina, y en el Brasil en particular, se realizó de forma singular, pues su población reunió tribus recolectoras hasta altas civilizaciones, todas ellas portadoras de culturas propias, constituyéndose en civilizaciones singulares. Razón por la cual propone una reformulación de las concepciones de la evolución sociocultural para servir de base a los estudios sobre el proceso de formación étnica.
Propone un nuevo esquema del desarrollo humano, objetivando un estudio de la formación de los pueblos americanos. Su meta es definir, de forma más precisa, las causas de la desigualdad del desarrollo de esos pueblos, ofreciendo criterios de clasificación. Su perspectiva antropológica abarca no apenas el aspecto científico sino que es construida mediante una postura hermenéutica, o sea, no se limita a explicar, sino también a interpretar en la medida en que intenta conocer la esencialidad de lo humano para sustentar su teoría.

Para lo cual, utiliza en su estructura teórica un esquema conceptual propio, redefiniendo conceptos de cierta forma ya de uso común. Denomina su antropología de dialéctica para distinguir de las antropologías adjetivadas como antropología cultural, estructural y antropología social. Su perspectiva antropológica se distingue de las demás orientaciones en la medida en que se funda en una teoría sobre la evolución sociocultural del ser humano que permite situar a las sociedades del pasado en un proceso de evolución idéntico al de las sociedades contemporáneas. Se apoya en una concepción de causalidad social en la cual reconoce el poder determinante de las innovaciones tecnológicas, el poder condicionante de las estructuras sociales y el carácter libertario o limitativo de las ideologías. Apela todavía para análisis conjeturales de las fuerzas 
sociales en interacción en cada situación histórica concreta. Toda la investigación llevada a término por Darcy Ribeiro tiene una preocupación y compromiso con el destino del ser humano concreto, una vez que analiza los efectos sociales de los estudios que emprende y los coloca al servicio de los pueblos que focaliza. Busca en la profundidad de las investigaciones, mas que una constatación científica, o una constatación por ella misma, un análisis riguroso acompañado de una crítica fundamentada en una visión de conjunto.

En su descripción histórica de las sociedades humanas como procesos resultantes de revoluciones tecnológicas y de la organización de las relaciones internas dentro de los grupos humanos, se constata que en ese proceso constante de evolución, el ser humano, en su esfuerzo contradictorio entre lo humano y la naturaleza, acumula en la conciencia conocimientos que son trasmitidos de una generación a otra y que convierten los recuerdos e imágenes en ideas y, a los pocos, consolidan el mundo de la cultura que va a identificar y singularizar los diferentes grupos humanos. La humanidad se va configurando en pueblos mediante el proceso de las revoluciones tecnológicas y de las relaciones socioculturales, dadas en intercambio con el ambiente natural $y$, en cuyo proceso se van consolidando los mundos culturales. Es importante percibir que el contacto con grupos étnicos distintos no interfiere, necesariamente, en las singularidades de las culturas. Al contrario, es dentro de la dinámica social que se plasma la identidad de cada grupo étnico, practicando innovaciones, apropiándose de descubrimientos ajenos mediante los cuales se van perfeccionando los modos de ser, desde que las alteraciones sean procesadas con autonomía dentro de las pautas de las propias culturas, y destinadas a servir a si mismas. Proceso que no ocurrió en la formación del pueblo brasilero, pues la violenta incorporación histórica impuesta por los portugueses llevó a transformar a los pueblos nativos y más tarde a los pueblos africanos, en pueblos destinados a producir excedentes para la manutención de los padrones de vida europeos.

El proceso de formación del pueblo latinoamericano no se procesó de forma natural, o sea, como el resultado de acciones intencionales generadas dentro de los propios grupos, mediante un intercambio deseado. Las relaciones con las nuevas culturas se establecieron de forma violenta bajo el yugo de la dominación colonial desencadenando una aculturación ${ }^{4}$ transfiguradora de sus pueblos, interfiriendo fuertemente en la descaracterización de esos seres humanos.

Sin embargo, esos pueblos, dentro de la dinámica social, se fueron reconstituyendo floreciendo, 
según Darcy Ribeiro, como nuevas entidades étnicas. En el caso brasilero el proceso de aculturación sufrido, no logró extinguir las características de sus matrices culturales que todavía se mantienen vivas en algunos grupos humanos y otras, sumadas a los flujos migratorios, están construyendo pueblos nuevos.
Los elementos antropológicos presentados por Darcy Ribeiro nos proporcionan una base teórica a partir de la cual podemos formular elementos para justificar la temática de la interculturalidad.

\section{La propuesta intercultural}

La historia de la filosofía de Raúl Fornet-Betancourt con su perspectiva intercultural, viene a atender nuestro propósito que es la búsqueda de una determinada filosofía que tenga como meta colaborar en la instauración de un diálogo intercultural en el contexto educacional brasilero, en la medida en que nos ofrece un aporte entre filosofía y antropología, exigencias éticas del reconocimiento de la identidad y su resistencia frente al mundo globalizado que nos envuelve. El autor nos presenta una perspectiva de la concepción de cultura según la cual la cultura no significa una esfera abstracta, reservada a la creación de valores espirituales, sino el proceso concreto por el cual una comunidad humana determinada organiza su materialidad basada en los fines y valores que quiere realizar.

Nos dice que no hay cultura sin materialidad interpretada $u$ organizada por fines y valores representativos y específicos de una sociedad o etnia humana. Afirma que las culturas no son evaluadas por la "altura" de sus valores espirituales o por el grado de formación intelectual de sus participantes. Lo que importa es "la capacidad de nuestras culturas para estar a la altura de lo que sus miembros hacen todos los días, desde la posible oración de la mañana hasta su comportamiento en el tráfico urbano" ${ }^{\prime 5}$. La preocupación de Fornet-Betancourt es cuestionar si nuestras culturas están en condiciones de dar a todas nuestras relaciones y situaciones históricas, una calidad distinta y más humana que la que nos dan las redes del mundo globalizado del tiempo que estamos viviendo. El autor expresa en sus abordajes acerca de la cultura, la temporalidad, la contextualidad, la intencionalidad, como características inherentes a las culturas, lo que justifica su renovación continua. Razón por la cual sólo es posible expresar, acerca de la cultura, concepciones fundamentas en perspectivas o cosmovisiones determinadas. Las culturas en su constante renovación están, esencialmente, vinculadas a las respuestas contextuales que los seres huma- 
nos dan a sus preocupaciones, sus necesidades, sus cuestionamientos, movidas por diferentes intereses, en un esfuerzo de establecer vínculos entre sus miembros con vistas a su ordenamiento. Razón por la que experimentan, en su interior, procesos que en su desarrollo natural envuelve tensiones y conflictos entre lo que está establecido y las innovaciones, dentro de una disputa de poder en que solamente la relación dialógica puede propiciar una interacción en el interior del grupo. Así, la dialéctica entre tradición e innovación, hace parte del flujo normal de cada cultura, movimiento que es inherente al proceso de humanización de seres portadores de las dimensiones de la razón y de la libertad, lo que justifica la necesidad de volver a contextualizar los saberes en general y, en particular, la filosofía, acompañando el proceso histórico-social del ser humano.

\section{Conciencia histórica}

Se hace necesaria la reconstrucción de la razón filosófica en las distintas culturas.

Nosotros latinoamericanos, heredamos por medio del proceso civilizador, la tradición occidentaljudeocristiana, la Ilamada razón occidental, considerándola, por largo tiempo, como el único lugar de manifestación de la verdad. A partir del avance de las investigaciones provenientes del campo de la antropología y de las ciencias sociales, se constató que, de cara a la diversidad de universos culturales, los cuales comportan estilos diferentes en cuanto a las formas de acceso a la experiencia, acceso al conocimiento, acceso a la realidad, se necesita cuestionar el modo de comprender la racionalidad occidental, pasando a concebirse una pluralidad de racionalidades, o sea, otras formas de acceso al conocimiento, a la verdad, reforzando la necesidad de que las distintas culturas de la humanidad participen del diálogo universal.

La propuesta pedagógica que defendemos, propone el diálogo intercultural que se coloca como alternativa para que las diferentes voces, brotadas de los diferentes contextos, puedan ser oídas y consideradas con el objetivo de mantener la pluralidad de las tradiciones culturales de los pueblos, en sus mundos y en sus tiempos.

El ser humano es concebido y se construye envuelto por la realidad concreta. Realidad que lo acoge e interfiere en su constitución. En momentos de la historia del pensamiento, en nuestra América, voces se elevaron en una toma de conciencia contra la imposibilidad de expresar la propia voz. Hoy el desafío es que las múltiples voces de la razón despiertas, se articulen, 
con vistas a establecer un diálogo intercultural pautado por diferencias históricas. Lo que sólo será posible, según Fornet-Betancourt, "entre sujetos que se interpelan y encaran, en libertad, la tarea de la recíproca comunicación".

La filosofía intercultural nos propone, aparte del rehacer la historia de la razón, una relectura de los procesos y de las prácticas contextuales, que interfieren en los distintos sectores de las sociedades humanas. El tiempo que estamos viviendo, indiferente a la repercusión sobre los seres humanos, es marcado por revoluciones científicas y tecnológicas difundidas e internalizadas por medio de estrategias sofisticadas de comunicación, aparentando ser, sus productos, la única opción para el conjunto de la humanidad. Política que interfiere, violentamente, en el control social y político de los pueblos, extendiéndose al dominio cultural nivelando los valores, los padrones de elección. Y, al vivir apurados para garantizar la subsistencia, corremos el riesgo de perder de vista la conciencia de nuestras reales necesidades entre ellas la construcción de los sueños, elemento que impulsa al ser humano a pensar.

Nuestro tiempo exige que sea desarrollada una hermenéutica de la liberación histórica lo que sólo ocurrirá en el momento en que los pueblos redescubran su palabra, pasando a comunicarse a partir de su alteridad.

Darcy Ribeiro nos muestra que el modelo colonialista al que fuimos sometidos, reunió en un único sistema político y económico grupos humanos autónomos, que regían sus vidas por cuerpos peculiares de costumbres y valores, determinándoles un modo de ser y de vivir. Proceso que empobreció las múltiples rostros de lo humano viniendo a generar la constitución de pueblos dependientes, tanto en el nivel cultural como cognitivo, los denominados "mestizos" ${ }^{\text {. }}$. Proceso de formación doloroso del pueblo brasilero que se fue reconstituyendo marcado por la discriminación proveniente de la tesis de la "pureza de las razas", pero que consiguió mantener aspectos de su identidad original, gracias al sincretismo que promovió una adaptación de lo propio con lo extraño y que acabó generando expresiones nuevas de ser y de estar en el mundo. Pero, la conciencia del extranjero dentro de si, resultó en culturas frágiles, porque desenraizadas de sus bases fundadoras.

Los pueblos viven en tiempos existenciales distintos. Darcy Ribeiro afirma que la

Población brasilera es constituida por un pueblo viejo y nuevo al mismo tiempo. Viejo porque aún mantenemos la función de provee- 
dores de bienes para el mercado mundial mediante el desgaste de la población y de su ambiente natural, no existiendo para su pueblo, sino para generar lucros exportables; pero un pueblo nuevo, porque aunque manteniendo marcas de la matriz portuguesa, nos singularizamos por la redefinición de trazos culturales provenientes de nuestra constitución, resultante de la fusión de diferentes matrices culturales y por la energía que emana de las clases oprimidas.

Las primeras matrices étnicas presentes en la constitución del pueblo brasilero fueron la indígena y la blanca portuguesa. Sin embargo, el proceso colonialista impuesto, llevó casi a la extinción de los pueblos originarios de la tierra como consecuencia de su negación como personas humanas.

Pero, más violenta que la dominación física fue la exigencia de renunciar a sus valores, sus formas de ser y vivir.

A partir del siglo XVII, los portugueses pasaron a importar esclavos de origen africana, acrecentando un nuevo elemento a nuestra constitución y que vino a influir de forma determinante en nuestra forma de ser y de aparecer. A pesar de la prohibición del uso de sus lenguas nativas, de expresar sus culturas, esos pueblos, provenientes de diferentes regiones del continente africano, aprendieron la lengua dominante y fueron imprimiendo en ella un ritmo especial colaborando en la formación de la lengua portuguesa brasilera.

Poco a poco fueron impregnando el contexto, trasmitiendo, además de los trazos fisonómicos, la cadencia, los sabores y sentimientos especiales que, fundidos con aspectos culturales indígenas, prestan a la cultura brasilera una fisonomía singular, maravillosamente heterogénea.

A pesar de la política homogenizadora promovida, especialmente, por la imposición de una lengua y de una religión, en la búsqueda de un padrón único de cultura, la extensión del territorio, la diversidad del contexto geográfico que obliga adaptaciones a la naturaleza, con climas, vegetación, topografía contrastantes, sumados a la naturaleza de las actividades desarrolladas, y al grado de libertad usufructuada, fuera de la incorporación de nuevos contingentes humanos, el Brasil resultó en un país constituido por núcleos poblacionales distintos, desarrollando en cada región identidades culturales singulares, razón por la cual Darcy Ribeiro compara el Brasil a un "archipiélago cultural". Los pueblos litorales, los pueblos de los bosques, los pueblos de las regiones de los grandes ríos, los pueblos de las áridas regiones agrestes (sertões), los pueblos de las pampas del sur, los habitantes de las grandes metrópolis, los pueblos migrantes. 
La heterogeneidad étnica brasilera queda manifiesta en las expresiones culturales de los pueblos y, aunque conviviendo y compartiendo armoniosamente en un mismo territorio, esa pluralidad cultural brasilera viene a reafirmar nuestro objetivo de que como educadores debemos trabajar en el sentido de la promoción de una actividad pedagógica norteada por una filosofía intercultural con el objetivo de que el diálogo, acción oriunda de las diferencias, se establezca colaborando en la superación de la dependencia colonial-esclavista aún presente en determinados grupos humanos, dando la oportunidad del rescate de sabidurías que corren el riesgo de perderse en el tiempo, rescatando los mundos de vida y la humanidad perdida por muchos.

Una práctica pedagógica iluminada por una filosofía que encamine las acciones concretas que garanticen la realización personal de los seres humanos considerando los diferentes tiempos en que viven, los distintos saberes y las formas propias de cada cultura organizar y expresar su pensamiento.

En el Brasil, las culturas campesinas y las también denominadas culturas populares son las que singularizan la identidad brasilera. Esas culturas se encuentran amenazadas por el proceso globalizador que por medio de los recursos de la comunicación y también por el proceso educacional que, intermediados por decisiones políticas, impone padrones culturales uniformes, está poniendo en riesgo la riqueza de la diversidad cultural de nuestro pueblo.

Darcy Ribeiro alerta, a través de su obra, que la ciencia y la técnica fueron puestas al servicio, fundamentalmente, de la producción de riqueza y de poder en las economías contemporáneas. $\mathrm{Y}$, en consecuencia, tales recursos desvinculados de lo humano, pasan a ocupar un lugar privilegiado en una sociedad que se estructura por los paradigmas del poseer y del dominar, comprometiendo el mantenimiento de la sabiduría del pueblo, la expresión oral, las tradiciones, únicas fuentes capaces de mantener el vínculo con la ancestralidad de los distintos universos culturales.

Admitimos los valores de la cultura llamada "desarrollada" en lo que atañe a su creatividad y valor. Lo que denunciamos es la superposición de una cultura, que por detentar el poder, se vale del aparato tecnológico del que dispone para imponer una pretendida hegemonía cultural, en una falta de respeto a los pueblos que pautan sus vidas por otros paradigmas.

En la perspectiva intercultural lo que se anhela es que los pueblos encuentren una forma que permita conciliar las ventajas provenientes de la evolución técnico-científica, pero de forma consciente, libre, a 
fin de que el acceso a los frutos de la civilización sea conciliado con la preservación de sus "caras éticas", de la singularidad y creatividad de sus componentes culturales propios.

La tarea de la transformación intercultural de la filosofía en un país constituido por una tan intensa heterogeneidad cultural parecería tarea fácil si no fuese por la dificultad en colocar de hecho, lo indígena y lo afro brasilero como elementos constitutivos de la formación de la identidad brasilera.
Hasta la década del 40 esos grupos humanos eran condenados, en el decir de Paulo Freire, a la cultura del silencio. Sólo a partir de mediados del siglo pasado esas etnias pasaron a figurar, formalmente, como integradas a la constitución del pueblo brasilero.

Sin embargo, todavía vivenciamos dificultades provenientes de la exclusión social que históricamente marcó a la sociedad brasilera, factores que colaboraron en la generación de culturas dependientes.

\section{Algunos presupuestos para la filosofía intercultural: consideraciones iniciales}

Aunque la filosofía intercultural no tenga como objeto el estudio o análisis de las Culturas ${ }^{7}$ en si, es indiscutible que su función está íntimamente ligada a una concepción de ser humano, tanto en su perspectiva ontológica como a su mundo relacional, una vez que el énfasis de su abordaje incide sobre los aspectos vinculados a las relaciones entre las culturas, y, por el hecho del ser humano ser un todo indisociable, la interferencia sobre cualquiera de sus dimensiones va a alcanzar la totalidad de su ser. Se sabe que la cultura determina, en cierta medida, al ser humano, una vez que carga consigo condicionamientos, tales como el uso de la libertad y de la razón. De ahí que provoca en el ser humano una tensión permanente, pues ella refuerza un modo de ser y hasta de pensar acumulado, lo que entra en conflicto con la naturaleza propia del ser humano, que es capacidad y necesidad de desarrollar su identidad personal en un proceso personal de apropiación crítica y de elección.

La vida humana es una inquietante tarea. El ser humano no vive cómodamente instalado, sino impulsado por una exigencia constante de adecuación al medio. Gracias a la libertad, que es un atributo del ser humano, a lo largo de su vivir, cada persona asume la responsabilidad de decidir por la apropiación de aquello que le es propio y que le fue trasmitido por su cultura de origen, atento también a la superación de aspectos culturales heredados, pero abierto, de forma consciente y responsable, a la adquisición de nuevos padrones de 
vida. Fornet-Betancourt denomina esa superación de aspectos culturales, factor normal en el proceso de humanización, de "desobediencia cultural". Gracias a ella se verifica la construcción de la biografía personal, que singulariza cada persona. Proceso inevitable y del cual depende la realización personal de cada ser humano.

\subsection{El compartir de vidas}

Además de los presupuestos ético-antropológicos, el saber acumulado por las tradiciones, la práctica de una filosofía intercultural va a exigir la comprensión de los saberes prácticos, o sea, aquellos que sirven de guía para responder a los desafíos de la construcción del camino de la vida y que las personas, dentro de sus respectivos contextos van creando. Así la participación de la vida, de lo cotidiano de las personas, se hace necesaria pues solamente así las distintas culturas se van relacionando, promoviendo una relación que nos permita leer e interpretar adecuadamente los diferentes contextos. Es una tarea difícil, pues va a exigir el contacto directo, el compartir de vidas, la narrativa.

La filosofía intercultural es un camino, no un punto de llegada. Un camino construido en una relación que se estructura de un pensamiento vivido, o sea, la filosofía intercultural sólo puede ser pensada dentro de una dinámica. El diálogo asume, de esa forma, parte esencial en nuestra reflexión. Un diálogo fundado en el reconocimiento mutuo entre los participantes basado en la existencia real de las diferencias y pautado por una armoniosa relación de poder entre las culturas, de modo de propiciar relaciones de aprendizaje en un ejercicio de convivencia. Diálogo entendido como "movimiento de conciencias" de forma que podamos comprender como el otro se ve a si mismo, a fin de que podamos percibir la relevancia, el peso y la importancia de cada cultura en nuestro esfuerzo de comprensión de sus aspectos fundadores. Un diálogo dirigido para el encuentro de personas integradas en un contexto, o sea, establecido con seres humanos en mediación con el mundo.

Para esto se requiere una práctica permanente en la superación de los modos de saber y de hacer, liberándose de la concepción de que cabe a una determinada cultura organizar e interpretar el mundo. Esas razones ponen como primer paso para esa transformación del filosofar, la reflexión criteriosa sobre nosotros mismos, a fin de que nos aseguremos de cual es nuestra postura en relación a las distintas culturas. Es fundamental también que se haga un profundo análisis de nuestra propia cultura y del modo como organizamos nuestros saberes. De esa toma de conciencia va a depender nuestra postura en relación a las demás culturas, afectando, o quizás alterando, la calidad de nuestras re- 
laciones y condiciones de vida, por lo tanto de nuestra acción.

\subsection{Porque somos lo que somos}

Otro presupuesto necesario para una filosofía intercultural es reflexionar acerca de la forma como ordenamos nuestro pensamiento, el origen de los conceptos que tenemos internalizados, la carga semántica de nuestro lenguaje. Aspectos que debemos considerar no para negarlos sino para que podamos, conscientes de nosotros mismos, dirigir una mirada, lo más pura posible, de predisposiciones conceptuales y valorativas, sobre el universo cultural. Valores y perspectivas internalizadas de cara a nuestra historia de sucesivas dominaciones vividas a lo largo del proceso civilizador y que, no raras veces, en gran medida, limita nuestra visión universal.

Precisamos tener conciencia de la lógica que nos conformó ${ }^{8}$ en un modelo de ser y de pensar que resultó en una tendencia a la hegemonía humana y cultural $y$, en consecuencia, generó espacios para la discriminación de todo orden. Necesitamos, para el ejercicio de una postura intercultural, ejercer una conciencia reflexiva y crítica sobre las ideas que manejamos tanto en el discurso como en la práctica. La exigencia inicial es la reflexión sobre nosotros mismos, sobre el contexto en el cual actuamos y con base en un enfoque metodológico hermenéutico encaminar nuestra reflexión para una práctica intercultural del diálogo entre los diferentes saberes. Esa práctica dialógica presupone una concepción personal interna de que los diversos rostros, idiomas, costumbres, tradiciones que expresan la diversidad de los humanos, nos enriquecen, más allá de eso por ser manifestaciones de la forma humana de ser, son elementos intocables, pues confieren identidad y singularidad al otro, que por naturaleza óntica, es distinto de nosotros.

\subsection{Presupuestos contextuales}

Necesitamos buscar la comprensión de los saberes prácticos, aquellos que sirven de guía para responder a los desafíos de la construcción del camino de la vida y que las personas, dentro de sus respectivos contextos, van creando. O sea, al lado del saber acumulado por la tradición, la práctica de una filosofía intercultural va a exigir que ese saber participe de la sabiduría del mundo y de la vida de lo cotidiano de las personas. Solamente en esa medida, las filosofías de las distintas culturas se van a relacionar, promoviendo una relación que nos permita leer e interpretar adecuadamente los diferentes contextos. Es una tarea difícil, pues va a exigir el contacto directo, el compartir de vidas, la narratividad. La experiencia contextual es algo muy complejo, porque necesitamos compartir con algo que está a veces por fuera de nuestro mundo referencial, de nuestra historia personal. 
Para eso tenemos que aprender no sólo ideas sino, y principalmente, contenidos que nos auxilien a movernos en los distintos contextos. El saber práctico, adquirido por el contacto personal, el compartir la vida por largos años con los pueblos que investigó es el principal factor que da credibilidad a la teoría de la cultura de Darcy Ribeiro.

\subsection{Resumiendo:}

Para hacer filosofía intercultural se tendría que, primeramente, poner las conceptualizaciones de filosofía en comunicación, intentando aprender a ver el asunto de la filosofía de fuera de todas las denominaciones, pues en nuestro tiempo, en que la historia y la intelectualidad exigen una transformación, lo importante no es conocer muchas definiciones, sino aprender a ver los procesos prácticos. Para eso son necesarias algunas exigencias fundamentales. Primero, participar de los procesos que generan la sabiduría del mundo y de la vida, elementos que dan sustentación a lo cotidiano, pues solamente por el camino del compartir y del intercambio de los procesos prácticos se puede dar la comunicación entre las filosofías. Lo que tenemos que aprender no son apenas ideas, sino contenidos que nos auxilien a movernos en los contextos, capacitándonos a leerlos e interpretarlos correctamente, en una perspectiva no hegemónica. Segundo, no limitarnos a leer libros, sino también compartir vidas, me- moria histórica y proyectos de aspiraciones. Tercero: considerar que quien está construyendo el mundo hoy, dándole una configuración mundial, influenciando las culturas, es un sistema económico capitalista, sistema que viene sustituyendo las dimensiones sustentadoras de la cultura por dimensiones de consumo, de privatizaciones. Cuarta exigencia, la de que el trabajo pedagógico, en una línea intercultural, tiene una dimensión política, en la medida en que colabora en la garantía de que, en la convivencia de los pueblos, la diversidad cultural sea considerada. Expresaríamos todavía como una quinta exigencia que hacer filosofía intercultural supone llevar en cuenta los saberes orales, pues la oralidad carga consigo una lectura interpretativa del mundo, pautada en un marco de valores. La oralidad, como instrumento para organizar la vida, tiene una importancia significativa en el proceso pedagógico, una vez que, mientras que en la escuela y en la universidad se vehiculan, predominantemente, los saberes que están dentro del sistema, la conversación sanciona saberes, decide procesos de juicio, ampliando el conocimiento y la capacidad de lectura del mundo de la vida. El saber oral fue puesto en un plano secundario en nuestras instituciones de enseñanza, en la medida en que las libertades fueron restringidas, pues, cuando la sociedad se estructura en formas definidas, el texto es fundamental para la expansión de la línea polí- 
tica sobre la cual se fundamentan las instancias de poder, o sea, el texto va a garantizar la enseñanza de aquello que se supone deba ser aprendido.

Nuestros sistemas educacionales se fundamentan en saberes establecidos $^{9}$, y no en procesos de pensamiento, de discernimiento de la realidad. Con eso, no se quiere condenar al olvido el saber acumulado, sino recordar que necesitamos considerar que la tradición también es dinámica y que se forma en la confrontación con los diferentes saberes. El acto pedagógico, dentro de una propuesta intercultural, debe, pues, proporcionar un diálogo con los diferentes tipos de saberes, buscando ver como los pueblos decidieron lo que querían saber, con el objetivo de redescubrir nuevas ideas de conocimiento.

Darcy Ribeiro ya nos enseñó que las culturas, como resultado de la acción intencional del hombre, en su búsqueda permanente de su forma humana de ser, no son estáticas. Los saberes, en la verdad, no son saberes puros desarrollados en completo aislamiento cultural. No tienen una singularidad, sino que son resultantes de un contexto que se constituyó en comunicación con los miembros de diferentes grupos humanos. Existe todo un intercambio, un proceso de comunicación anterior a la fijación de los saberes. La interculturalidad, aunque como nomenclatura sea reciente en nuestro contexto ${ }^{10}$, como proceso, acompaña la historia de los pueblos. En cambio, como propuesta pedagógica es reciente.

La nueva propuesta pedagógica nos remite a la inseguridad de lo nuevo, pues exige el rompimiento con los paradigmas heredados de la cultura europea occidental, proponiéndonos una forma de filosofar que es movida por una convicción ética de respeto a todo el ser humano, en la medida en que se pauta por la apertura a otros modelos de racionalidad, de fuentes, de temáticas y métodos, oriundos de los distintos universos culturales.

Consecuentemente, la fundamentación y el contenido de la filosofía intercultural deben brotar de los contextos del mundo históricocultural, retornando a su real tarea y su sentido original, perdidos en la dimensión académica, que es la confrontación práctico-reflexiva con los contextos de la vida.

Surcar el camino de la interculturalidad es correr el riesgo de la inseguridad de lo desconocido, una vez que nos coloca en confrontación con el distinto de nosotros. Cada grupo humano construye su identidad a partir de las relaciones sociales que establece en su grupo, mediado por un contexto. Siendo así, el sentido de las expresiones culturales sólo puede ser comprendido en referencia al universo de significados propios de cada grupo 
humano. Riesgo que precisamos correr al asumir una ética de responsabilidad con el contexto en el cual vivimos.

Se sabe que ninguna tradición cultural puede conocerse a fondo a si misma ni detectar todas sus posibilidades inherentes, o sus propias limitaciones. De la misma forma ninguna cultura, ninguna filosofía, puede abarcar todas las posibilidades de la humanidad en sus diferentes formas de ser y de hacer. De ahí la exigencia de experimentar y reflexionar la riqueza de la vida, del cosmos, de lo humano, de lo divino, de todo lo que existe, en una perspectiva intercultural, entre la cultura dominante y los demás paradigmas particulares.

En el contexto brasilero, sumándose a la necesidad de superar las marcas resultantes de la herencia colonial, otro agravante de los tiempos que estamos viviendo viene a poner en riesgo la integridad de la heterogeneidad de las culturas: la globalización, que nos orienta para un proceso de uniformidad política y económica $y$, en consecuencia, cultural, sustentada por poderes que se sobreponen a la autonomía de los Estados Nacionales. La filosofía intercultural critica las consecuencias antropológicas y cosmológicas de ese proceso homogenizador, proponiendo la creación de mundos alternativos que por intermedio de intercambio permanente entre las diferentes culturas, busque un equilibrio de las particularidades.

En síntesis, de cara a la heterogeneidad cultural del pueblo brasilero, necesitamos pasar de un modelo filosófico monocultural a otro, que sería el intercultural. Líneas que alcanzan no apenas la perspectiva de trabajo, sino, y principalmente, una disposición de vida. La propuesta intercultural nos invita a transformar nuestro filosofar en un saber que mediado por la teoría y por la práctica, aproxime los seres humanos y sus culturas al mundo de hoy. Su tarea, pues, traspasa el mundo de los textos para ocuparse de los contextos del mundo histórico de los humanos de hoy. Propuesta que implica exigencias personales permanentes, tales como: la reflexión criteriosa sobre nosotros mismos; el análisis de nuestras propias culturas; la conciencia del modo como organizamos nuestros saberes; el origen de los conceptos que tenemos internalizados; la carga semántica de nuestro lenguaje, condiciones para que podamos, conscientes de nosotros mismos, dirigir una mirada, la más pura posible de predisposiciones conceptuales y valorativas, sobre el universo cultural. Propuesta que fuera de exigir una reflexión personal acerca de los límites de nuestra cultura y de la disposición de aprender con las otras culturas supone que no disolvamos nuestra propia originalidad sino que nos 
enriquezcamos por medio de una relación que supone una valorización mutua de parte de aquellos que interactúan, con el objetivo de una acción capaz de promover una práctica establecida por el diálogo entre los diferentes saberes.

\section{Diálogo intercultural}

Enumeramos algunos presupuestos para la práctica de una filosofía intercultural destacando el ejercicio del diálogo intercultural como exigencia, no sólo para el reconocimiento de la igualdad en las diferencias, sino también para la construcción de una práctica compartida con intereses y responsabilidades comunes.

La cultura, generalmente opera con un modelo mental totalizador, o sea, modelo que fija y cierra la verdad en ella misma. Para el diálogo de las culturas es necesario despojarnos de ese modelo. Fornet-Betancourt nos alerta para la necesidad de un cambio de actitud delante de la "verdad", modelo de verdad que no es, ni condición ni situación, sino proceso. Eso supone que ninguna posición cultural puede entenderse como lugar definitivo de la verdad y mucho menos, como expresión absoluta. "Las culturas no dan la verdad, y si posibilidades para buscarla; son referencias para poner en marcha el proceso discursivo de la verdad"11. En la búsqueda de la verdad, es necesario el establecimiento de una relación en la cual los interlocutores participen del intercambio cultural en igualdad de condiciones, acep- tando el aprendizaje recíproco, en que la verdad se va desvelando mediante la dialéctica creada por la confrontación de posiciones. Siendo así, la interdiscursividad es exigencia fundamental en el diálogo de las culturas.

Dada la naturaleza histórica de las culturas, ellas cargan en si conflictos naturales de la especificidad humana. Conflictos que la historia tiene que considerar y fomentar en el sentido de colaborar para la generación, en el interior de cada cultura, formas de ser que no se pauten apenas por tradiciones pasadas, sino que las proyecten para una realidad abierta a nuevos procesos de interacción.

El ser humano, ontológicamente constituido por la calidad de la libertad, en su proceso de humanización no vive instalado en una situación ya definida. Vivir es una tarea inquietante en la cual todo ser humano necesita ir respondiendo a los conflictos naturales que la vida presenta. Esa hermenéutica hace con que, dentro de las culturas haya, permanentemente, un proceso dinámico de superación, apropiación de lo nuevo que se coloca. 
Fornet-Betancourt, en una conferencia proferida ${ }^{12}$, refiriéndose al proceso natural de humanización atribuyó como tarea de la filosofía la "desobediencia intercultural" con el objetivo, con esa expresión de Ilamar la atención para el hecho de que, aunque toda cultura tenga el derecho de ver el mundo por si misma, eso no significa el permiso para imponer a sus integrantes, como única visión que deben compartir. Esa exigencia visa a respetar la dignidad de cada ser humano, o sea, de hacer de su cultura una opción personal de forma que el estar inserido en una cultura determinada no signifique estar sometido a una situación de dependencia. Alcanzar la forma humana de ser presupone a cada individuo, un hacer y rehacer, un optar permanentemente ante los desafíos que el vivir proporciona a lo largo de la existencia. Ahora, el sujeto humano, en la medida que toma pose de si mismo, tenga el derecho natural de poder optar por una posición, $y$, a partir de la toma de posición de la memoria de las tradiciones de su cultura, adoptarlas o buscar otros soportes culturales.

La filosofía tiene exactamente ese papel, el de estimular, en cada cultura, la retomada constante del conflicto de tradiciones que, por vía de regla, es ocultado en la tendencia dominadora del mantenimiento de un orden ya establecido. Cabe, por lo tanto, a la filosofía estimular y mantener viva, al interior de cada cultura la dialéctica entre libera- ción y opresión a fin de que las transformaciones de las culturas se procesen basadas en una propuesta ética, en la cual toda y cualquier cultura participe en su dinamismo transformador natural, sin presión y exclusión de sus sujetos reales.

La filosofía debe ser, aún más, un instrumento capaz de actuar al interior de las culturas de forma de evitar que determinadas culturas se coloquen como verdaderos monumentos intocables. La historia nos atestigua que la sacralización de ciertos contenidos culturales es la responsable por gran parte de las tragedias que asolan la humanidad. En ese sentido, la filosofía intercultural se opone a la tendencia multicultural anunciada como inevitable en nuestro tiempo y que, desastrosamente, encamina para promover una cultura común.

La filosofía que buscamos viene a proponer, en principio, crear condiciones favorables que propicien el ejercicio del diálogo entre las culturas por medio de procesos de interacción expresados por experiencias concretas de comunicación. Solamente el diálogo va a permitir un reconocimiento de la igualdad, mismo en las diferencias, colaborando para la construcción de una práctica compartida con intereses y responsabilidades comunes. Para eso, se precisa buscar la convivencia de los diferentes, manteniendo las peculiaridades culturales de cada uno, creando condiciones para 
que se establezca un marco dialogal basado en la diferencia y, teniendo claro que ser diferente no significa ser desigual.

Siempre es importante reafirmar que partimos del principio de que existen prácticas culturales de filosofía, ${ }^{13}$ o sea, el ejercicio concreto del pensar en los distintos espacios culturales. Es importante percibir, como nos enseña FornetBetancourt, "que la filosofía es plural en su forma de articularse, de organizarse o de institucionalizarse". Siendo así, se torna evidente la pluralidad de prácticas culturales de la Filosofía, una vez que esta se ocupa de la realidad. La filosofía, pues, tiene una dinámica histórica, una vez que nace en una multiplicidad de lugares, cargando consigo las diferencias en la forma como se desenvuelve y se relaciona con el contexto en el cual es articulada.

Si nos detuviéramos en la historia del pensamiento, vamos a constatar que él es resultante de las relaciones contextuales en las cuales es generado como expresión de una realidad.

\subsection{Para un diálogo intercultural con la pluralidad cultural brasilera}

La interrelación cultural es una realidad presente en la formación del pueblo brasilero, desde su constitución como nación. La cultura dominante es constituida por la fusión de grupos étnicos distintos, la denominada "cultura mestiza". Sin embargo otras culturas $^{14}$ viven y comparten la realidad brasilera, factor que interfiere en el proceso de formación de una identidad propia de su pueblo. Eso justifica la exigencia de un diálogo en todos los campos, especialmente en el intelectual, postura que debería haber merecido la atención a lo largo de toda la historia brasilera.

Se sabe que la identidad es consecuencia de un proceso de identificación social, ética y cultural dentro de un grupo. La identidad es la que permite el reconocimiento, asegurando a los seres humanos un lugar dentro del contexto en el cual conviven. La diversidad de los pueblos y culturas fue motivadora de innúmeros conflictos en la formación de nuestra nación. Conflictos resultantes de los cambios impuestos por los colonizadores que obligaban no sólo a los pueblos nativos sino también a los inmigrantes a un cambio de valores con vistas a la homogeneización cultural. Ninguna lengua de los pueblos originarios, como la Tupí y sus derivadas, fueron adoptadas, aunque un número expresivo de naciones que coexisten con la nación brasilera, se comuniquen en esos idiomas. ${ }^{15}$

En los documentos que tratan de los derechos de los pueblos originarios, lo que se percibe como preocupación, con algunas excepciones, es la creencia de que la cuestión indígena es la falta de in- 
tegración social y económica como si lo indígena ya no existiese como sujeto de una cultura distinta. Estas razones justifican la urgencia y la responsabilidad de los intelectuales y pensadores para que, superando la cultura académica, trabajen en el sentido de que el desafío intercultural sea estimulado con vistas a que el derecho a la autodeterminación política, cultural y religiosa de esos pueblos, encuentre condiciones de ejercicio.

En Brasil, sólo recientemente y en rarísimos currículos escolares, es contemplado el estudio de las culturas y del pensamiento africano, mismo siendo reconocido su lugar de destaque en la formación de nuestra identidad, expresado en todos los sectores de la vida brasilera. Lo mismo ocurre con las culturas indígenas, en un testimonio de que la descolonización de nuestras mentes aún no se efectuó. Biológicamente somos la síntesis del indio, del blanco europeo y del africano, pero leemos e interpretamos el mundo a partir del paradigma impuesto por el poder de la cultura blanca.

La resistencia experimentada en la academia a la adopción de un nuevo modelo de filosofar es generada por la dificultad en asumir el desafío desestabilizador, propuesto por el diálogo intercultural, que consiste en asumir la novedad que es la de establecer relación entre sujetos que se interpelan y que encaran, en libertad, la tarea de la recíproca comunicación. Mientras, es imperioso asumir, con responsabilidad, que los otros - indígena, afro-brasilero- no pueden convertirse en "objeto de interés" u "objeto de investigación" porque el ser humano no es una mera materia para ser analizada, comparada por un pensamiento dispuesto a asimilarlo como "pensado", o "conocido", sino como sujeto de un pensamiento propio y en proceso.

\subsection{El diálogo intercultural como camino}

El diálogo intercultural es el camino por el cual la filosofía gana un nuevo acceso en dirección de si misma, en la medida en que propone la superación del horizonte conceptual, paradigma de la tradición filosófica occidental, desvinculándola de la comprensión de constituirse por un saber técnico capaz de alcanzar un grado de expresividad, de abstracción y reflexión, obedeciendo a un método predeterminado. Darcy Ribeiro, aunque no sea contemporáneo del término "interculturalidad", ya expresa en su obra una percepción intercultural de la realidad brasilera, cuando afirma que los pueblos latinoamericanos, por su hibridad étnica, son los pueblos que mayor potencial ofrecen para un diálogo del mundo, una vez que incorporan más rostros raciales y culturales del ser humano. Afirma que son más disponibles porque permanecen abiertos a todas las influencias y se 
inspiran en una ideología que integra todas las razas.

Por otro lado, Raúl FornetBetancourt, en su obra, nos ofrece una idea similar cuando analiza la aproximación intercultural del pensamiento latinoamericano. Declara, que en nuestro mundo americano, ya estamos, de cierto modo delante de una herencia polifónica, la cual, siendo redescubierta y recuperada, ya nos ofrecería una base inicial para ejercitarnos en la perspectiva de que sumando deseos, esperanzas y especialmente acciones concretas por medio de un trabajo interdisciplinario podremos colaborar para el rechazo de la política dominante que trabaja en el sentido de la promoción de una homogeneización cultural, posibilitando que los distintos grupos humanos del Brasil puedan, sin renunciar a sus valores, sus etnias, sus creencias unirse en torno a proyectos con vistas a encontrar alternativas que encaminen hacia una sociedad más humana y fraterna.

\section{Conclusión:}

Concluimos que se hace necesario que la discusión en torno de una nueva forma de filosofía prosiga. Una filosofía que no se limite al estudio exegético del mundo de los textos, pasando a ocuparse de forma más atenta y cuidadosa con los contextos de los mundos históricos de los seres humanos. Que se hace necesaria la búsqueda de caminos culturales que favorezcan que las diferentes culturas puedan manifestarse juntas, cada una dentro de su universo cultural, con vistas a establecer una convivencia solidaria y cooperativa entre los distintos grupos humanos, pues solamente por medio del aparato emocional de la solidaridad se vuelve posible nuestra identificación con el otro y de nosotros mismos con el otro.

La filosofía no se vincula a un modelo paradigmático. Hay prácticas culturales de filosofía, o sea, ejercicios concretos de pensar que se hacen en cada contexto e historicidad. Y, si la heterogeneidad es la característica cultural de nuestro país, se concluye, que es necesario contextualizar también las formas de expresiones filosóficas, abriendo el horizonte del quehacer filosófico para otras formas de ejercicio. La riqueza del discurso oral de gran parte de nuestra población, que no dispone de la posibilidad de la palabra escrita, pero que, no por eso, está desprovista del pensar "racional" y de la vida, tiene que ser escuchada dentro de la sinfonía de las múltiples voces brasileras. Necesitamos "recuperar el ejercicio de la filosofía no por la instrucción, sino por la interlocución", como afirmó Fornet-Betancourt.

Finalmente, afirmamos que en el momento, la filosofía intercultural es la propuesta filosófica capaz de interferir en el debate educacional brasilero en la medida en que opera 


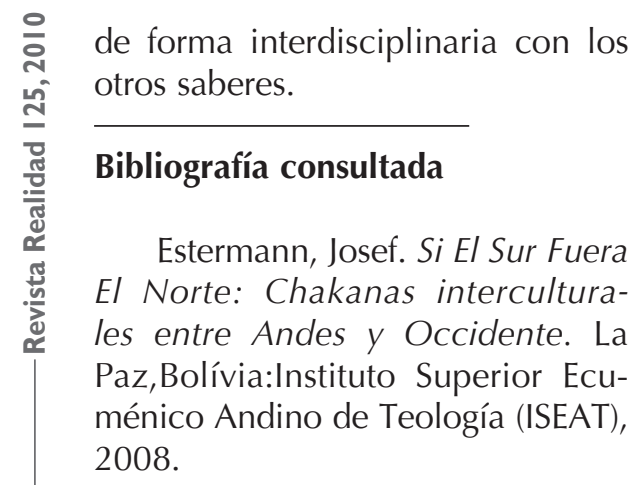

Fornet-Betancourt, Raúl. Transformación Intercultural de La Filosofía. Bilbao: Editorial Desclée de Brouwer. S.A., 2001.

Ribeiro, Darcy. O Processo Civilizatório: etapas da evolução sócio-cultural. São Paulo. Companhia das Letras, 1999.

Vaz e Silva, Neusa.Teoria da Cultura de Darcy Ribeiro e a Filosofia Intercultural. Tesis de doctorado en Filosofia Iberoamericana. El Salvador: UCA, 2008.

\section{NOTAS}

1 Doctora en Filosofía Iberoamericana por la Universidad Centro Americana José Simeón Cañas.

2 Processo Civilizatório es la obra fundamental que sustenta nuestra investigación. Libro que resultó del esfuerzo del autor para establecer criterios de clasificación de los pueblos americanos. Para eso Darcy Ribeiro amplió su perspectiva de análisis en el tiempo y en el espacio

viniendo a elaborar una primera esquematización de los pasos de la evolución tecnológica, social e ideológica de las sociedades humanas. El autor presenta un nuevo abordaje del proceso civilizador pues sus tesis resultan de la multiplicidad de experiencias que vivió observando el funcionamiento de la cultura en las condiciones más diversas pues convivió con pueblos en su etapa más primitiva e integró los liderazgos de las naciones modernas. Su obra posibilita tratar las sociedades avanzadas y las llamadas atrasadas no como etapas sucesivas de la evolución humana, sino como polos interactivos de un mismo sistema socio económico.

3

Orientación de su formación académica.

Darcy Ribeiro, al tratar la dinámica cultural de la formación de los pueblos brasileros utiliza la categoría aculturación, para expresar la incorporación a los modos de vida asimilados por los pueblos nativos y africanos, ocasionado por el proceso violento emprendido por el colonizador sobre esos pueblos. Resultó de la negación de la dignidad de esas etnias imponiéndoles una cultura que les era extraña, comprometiendo sus culturas ancestrales, bien como en la pérdida de sus identidades, en el descreimiento en sus propios valores. Esa violencia se verificó también en el proceso educacional utilizado por los misioneros, en la medida en que negaban las creencias 
y los valores que orientaban y daban sentido a la vida de esos pueblos.

5 Fornet-Betancourt, Raúl. Transformación Intercultural de la Filosofía, p. 233.

6 Darcy Ribeiro en la Obra Os Brasileiros, escribe: "Nosotros, brasileros, somos un pueblo en ser, impedido de serlo. Un pueblo mestizo en la carne y en el espíritu, ya que aquí el mestizaje jamás fue crimen o pecado. En él fuimos hechos y todavía nos continuamos haciendo. Esa masa de mestizos vivió por siglos sin conciencia de si... Así fue hasta definirse como una nueva identidad étnico-nacional, la de brasileros... pues en el estudio del proceso por el cual la sociedad y la cultura brasilera se vienen plasmando, se observa como las matrices culturales indígenas, africana y europeas entraron en conjunción, primero para componer, a través de la interacción de sus elementos, algunas células culturales nuevas con respecto a las células originales y, después, para fundirlas en una proto-etnia con la cual la población se va identificando". Obra citada. p. 140.

7 Campo de estudio de la Filosofía Cultural

8 Inicialmente por el proceso civilizador colonial con una educación para la dependencia, después por los innúmeros regímenes políticos represivos totalitarios, hoy por la globalización neoliberal que estimula la hegemonía.

$9 \quad$ Ver Josef Estermann, obra citada, p 29-30.

También sobre la cuestión, Raúl Fornet-Betancourt en la obra Religião e Interculturalidade, Capítulo V.

El término interculturalidad aún no figura en los diccionarios de lengua portuguesa.

11 Fornet-Betancourt, Raúl. Transformación Intercultural de la Filosofía, p.48.

12 Conferencia pronunciada en el Seminario Internacional: La Filosofía Intercultural de cara a los Desafíos de la Globalización, celebrado en UNILASALLE, Canoas/RS en el mes de mayo de 2003.

Filosofías contextuales.

14

Datos estadísticos apuntan a la existencia de un promedio de 150 etnias distintas entre los pueblos indígenas brasileros. Sin contar los afro-descendientes y los innumerables inmigrantes.

Hoy la lengua de señales "libres" es también lengua oficial en el país, aunque su enseñanza sea facultativa. 